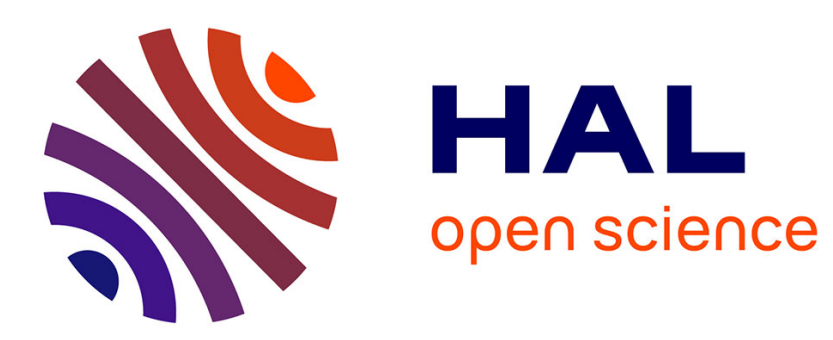

\title{
Ab initio investigations of the electronic structure and chemical bonding of Li2ZrN2
}

\author{
Samir F. Matar, Rainer Pöttgen, Adel F. Al Alam, Naïm Ouaïni
}

\section{To cite this version:}

Samir F. Matar, Rainer Pöttgen, Adel F. Al Alam, Naïm Ouaïni. Ab initio investigations of the electronic structure and chemical bonding of Li2ZrN2. Journal of Solid State Chemistry, 2012, 190, pp.191-195. 10.1016/j.jssc.2012.02.038 . hal-00700243

\section{HAL Id: hal-00700243 \\ https://hal.science/hal-00700243}

Submitted on 24 May 2012

HAL is a multi-disciplinary open access archive for the deposit and dissemination of scientific research documents, whether they are published or not. The documents may come from teaching and research institutions in France or abroad, or from public or private research centers.
L'archive ouverte pluridisciplinaire HAL, est destinée au dépôt et à la diffusion de documents scientifiques de niveau recherche, publiés ou non, émanant des établissements d'enseignement et de recherche français ou étrangers, des laboratoires publics ou privés. 


\title{
Ab initio investigations of the electronicstructure and chemical bonding of $\mathrm{Li}_{2} \mathrm{ZrN}_{2}$
}

\author{
S. F. Matar, R. Pöttgen, A. F. Al Alam, N. Ouaini \\ Published in Journal of Solid State Chemistry 2012, vol. 190, p. 191-195.
}

\begin{abstract}
:
The electronicstructure of the ternary nitride $\mathrm{Li}_{2} \mathrm{ZrN}_{2}$ is examined from abinitio with DFT computations for an assessment of the properties of chemicalbonding. The compound is found insulating with $1.8 \mathrm{eV}$ band gap; it becomes metallic and less ionic upon removal of one equivalent of Li. The chemical interaction is found mainly between $\mathrm{Zr}$ and $\mathrm{N}$ on one hand and $\mathrm{Li}$ and $\mathrm{N}$ on the other hand. While all pair interactions are bonding, antibonding $\mathrm{N}-\mathrm{N}$ interactions are found dominant at the top of the valence band of $\mathrm{Li}_{2} \mathrm{ZrN}_{2}$ and they become less intense upon removal of Li. From energy differences the partial delithiation leading to $\mathrm{Li}_{2-x} \mathrm{ZrN}_{2}(x=\sim 1)$ is favored.
\end{abstract}

\section{I ntroduction}

In recent decades several classes of non-oxide lithium compounds were investigated for their use as negative electrode materials in lithium-ion batteries [1] and [2]. Besides silicides [3] and [4], sulfides [5] and [6] and phosphides [6], lithium transition metal nitrides [6] and [7] were examined as promising anode material. Along with the many phase analytical and electrochemical studies of such materials, comparatively few investigations focused on the electronicstructure and chemicalbonding, e.g. for $\mathrm{Li}_{15} \mathrm{Si}_{4}$ [8] or $\mathrm{Li}_{x} \mathrm{FeS}_{2}$ [9].

In the course of our systematic studies of structure-property relationships and chemicalbonding of binary and ternary lithium-based silicides ([4], [10], [11], [12], [13], [14], [15] and [16], and references therein) we recently investigated the electron precise silicides $\mathrm{YLiSi}\left(\equiv \mathrm{Y}^{3+} \mathrm{Li}^{+} \mathrm{Si}^{4-}\right.$ ) [16] and $\mathrm{La}_{2} \mathrm{Li}_{2} \mathrm{Si}_{3}\left(\equiv 2 \mathrm{La}^{3+} 2 \mathrm{Li}^{+} 2 \mathrm{Si}^{2-} \mathrm{Si}^{2-}\right.$ ) [15]. Such materials are potential candidates when searching for lithium mobility. Indeed, the calculations for YLiSi [16] indicated the possibility of an at least partial delithiation $\mathrm{Li}_{1-x} \mathrm{YSi}$, while keeping the yttrium-silicon substructure. Extending this work we were interested in the bonding patterns of related lithium nitridometalates $\mathrm{Li}_{x}\left[T_{y} \mathrm{~N}_{z}\right]$. Out of the huge number of lithium nitridometalates [17], [18], [19], [20], [21] and [22] we choose the structure of Li $\mathrm{ZrN}_{2}$ [23] and [24]. This nitridometalate was first synthesized by Palisaar and Juza in 1971 from a reaction between lithium nitride $\mathrm{Li}_{3} \mathrm{~N}$ and nitrogen excess $\mathrm{ZrN}_{1.22}$ in an ammonia flow at high temperature [23]. The structure was determined by powder X-ray diffraction without further characterization of its physical properties. Later on, Niewa and Jacobs reinvestigated $\mathrm{Li}_{2} \mathrm{ZrN}_{2}$ by neutron powder diffraction [24]. They fully confirmed the original structural model, however, with better precision, especially for the weakly scattering (X-rays) lithium atoms.

$\mathrm{Li}_{2} \mathrm{ZrN}_{2}$ has been studied with respect to the electrical conductivity, by solid state NMR spectroscopy [25], and coulometric titration [26], indicating that this nitridometalate might be suitable for high-temperature lithium batteries. Keeping these favorable properties in mind we studied the electronicstructure and the properties of chemicalbonding and potential delithiation of $\mathrm{Li}_{2} \mathrm{ZrN}_{2}$ within the quantum theoretical framework of the density functional theory (DFT) [27] and [28].

\section{Computational methodology}

Two computational methods within the DFT were used in a complementary manner. The Vienna abinitio simulation package (VASP) code [29] and [30] allows geometry optimization and total energy calculations. For this we use the projector augmented wave (PAW) method [30] and [31], built within the generalized gradient approximation (GGA) scheme following Perdew, Burke and Ernzerhof (PBE) [32]. The conjugate-gradient algorithm [33] is used in this computational scheme to relax the atoms. The tetrahedron method with Blöchl corrections [31] as well as a Methfessel-Paxton [34] scheme were applied for both geometry relaxation and total energy calculations. Brillouinzone (BZ) integrals were approximated using the special k-point sampling of Monkhorst and Pack [35]. The optimization of the structural parameters was performed until the forces on the atoms were less than $0.02 \mathrm{eV} / \AA$ and all stress components less than $0.003 \mathrm{eV} / \AA^{3}$. The calculations are converged at an energy cut-off of $400 \mathrm{eV}$ for the plane-wave basis set with respect to the k-point integration with a starting mesh of $4 \times 4 \times 4$ up to $8 \times 8 \times 8$ for best convergence and relaxation to zero strains. 
Then all-electron calculations, equally based on the DFT with the GGA-PBE functional [32], were carried out for a full description of the electronicstructure and the properties of chemicalbonding. They were performed using the full potential scalar-relativistic augmented spherical wave (ASW) method [36] and [37]. In the ASW method, the wave function is expanded in atom-centered augmented spherical waves, which are Hankel functions and numerical solutions of Schrödinger's equation, respectively, outside and inside the so-called augmentation spheres. In the minimal ASW basis set, we chose the outermost shells to represent the valence states and the matrix elements were constructed using partial waves up to $I_{\max }+1=3$ for $\mathrm{Zr}$ and $I_{\max }+1=2$ for $\mathrm{Li}$ and $\mathrm{N}$. Self-consistency was achieved when charge transfers and energy changes between two successive cycles were below $10^{-8}$ and $10^{-6} \mathrm{eV}$, respectively. The Brillouin zone integrations were performed using the linear tetrahedron method within the irreducible wedge [31]. The calculations are carried out assuming spin degenerate configuration. Besides the site projected density of states, we discuss qualitatively the pair interactions based on the overlap population analysis with the crystal orbital overlap population (COOP) [38]. In the plots, positive, negative, and zero COOP magnitudes indicate bonding, antibonding, and non-bonding interactions, respectively. We note that another scheme for describing the chemicalbonding, the ECOV (covalent bond energy) criterion based on both the overlap and the Hamiltonian populations is also accessible within the ASW method [37]. It provides similar qualitative results to the COOP.

\section{Crystal structure}

The trigonal structure (Table 1) of $\mathrm{Li}_{2} \mathrm{ZrN}_{2}$ [23] and [24] is sketched in Fig. 1. Along the $c$-axis it consists of a succession of $\mathrm{Zr}-\mathrm{N}-\mathrm{Li}$ layers, with Li tetrahedrally coordinated to $\mathrm{N}$ while $\mathrm{Zr}$ is found in an octahedral nitrogen environment. The shortest interatomic distances occur for $\mathrm{Li}-\mathrm{N}(2.098 \AA)$ and $\mathrm{Zr}-\mathrm{N}(2.253 \AA)$, compatible with the sum of the covalent radii of $1.93 \AA$ and $2.15 \AA\left(r_{\mathrm{Li}}=1.23 \AA, r_{\mathrm{Zr}}=1.45 \AA\right.$ and $\left.r_{\mathrm{N}}=0.70 \AA\right)$. Thus significant bonding can be expected for $\mathrm{Li}-\mathrm{N}$ and $\mathrm{Zr}-\mathrm{N}$ in the ternary nitride. This is explained further in next sections.

\section{Results of geometry optimizations, energies and electron localization}

Geometry optimization was carried out for $\mathrm{Li}_{2} \mathrm{ZrN}_{2}$ starting with the literature data [24]. Table 1 provides the experimental and calculated crystal structure characteristics. The geometry optimized lattice parameters and atomic positions are found in fairly good agreement with the experimental X-ray [23] and neutron powder determination data [24], especially for the internal coordinates of $\mathrm{N}$ and $\mathrm{Li}$. In order to examine the effect of lithium de-intercalation, two additional calculations were done assuming a departure of one out of the two lithium atoms leading to the composition " $\mathrm{LiZrN}_{2}$ " and a hypothetic lithium-free compound " $\mathrm{ZrN}_{2}$ ". The results are given in 3rd and 4th columns of Table 1.

The full geometry relaxation keeps the trigonal structure within space group $P 3^{-} m 1$ with a reduction of the $c / a$ ratio due to the departure of $\mathrm{Li}$. This is especially visible for the fully de-lithiated compound resulting into " $2 \square_{\mathrm{Li}} \mathrm{ZrN}_{2}$ ", where $\square_{\mathrm{Li}}$ designates a lithium vacancy, characterized by a largely reduced $c / a$ ratio of 1.28 . The internal atomic positions are also modified but the major changes occur for the cell volume which is only slightly reduced upon the departure of one lithium but largely reduced by $\sim 10 \AA^{3}$ for the departure of two lithium atoms and the reduction of the c/a ratio from 1.62 for " $\square_{L i} L_{i Z r N}$ " down to 1.28 for " $2 a_{L} Z Z_{Z}{ }_{2}$ ". Also it can be noted that the departure of one lithium leads to a shorter $\mathrm{Li}-\mathrm{N}$ distance and a reduction of the $\mathrm{Zr}-\mathrm{N}$ separation. This translates a stronger overall bonding in " $\square_{L} L L_{i} Z_{r}{ }_{2}$ ".

These results would indicate less perturbation of the structure with one lithium equivalent departed and large changes when a second lithium equivalent is removed. The calculated total energies can be used to assess the free energy of the process. For this purpose we further calculate lithium metal with the same potentials and method to obtain a total energy per atom of $-1.909 \mathrm{eV}$. Using the total energy values in Table 1, the Gibbs free energy change in the deintercalation process of $\mathrm{Li}_{2} \mathrm{ZrN}_{2}$ is:

For the removal of one lithium equivalent:

$\Delta G_{1}=E\left(L_{2} Z r N_{2}\right)-E(L i)-E\left(\square_{L i} L i Z r N_{2}\right)=-2.47 \mathrm{eV}$.

For the removal of a second lithium equivalent:

$\Delta G_{2}=E\left(\square_{L i} L i Z r N_{2}\right)-E(L i)-E\left(2 \square L i Z r_{2}\right)=-3.49 \mathrm{eV}$.

Both $\Delta G_{1}$ and $\Delta G_{2}$ values are larger than the ones obtained for the binary silicide $\mathrm{Li}_{15} \mathrm{Si}_{4}(\Delta G=-1.136 \mathrm{eV}$ [8]) and the ternary silicide YLiSi $(\Delta G=-1.69 \mathrm{eV}[16])$. They correspond, with inverse sign, to the average de-intercalation voltage, $V$. It is interesting to note the 1.4 times larger magnitude for the removal of the second lithium equivalent, 
which is concomitant with a smaller Li-N distance, leading to a significant stabilization of the mono-delithiated compound. The de-intercalation voltage for the removal of one lithium equivalent, $2.47 \mathrm{~V}$, is intermediate between the highest voltage magnitudes for the lithium intercalation compounds $\mathrm{LiTO}_{2}$ ( $T=3 d$ transition metal) [39] with values amounting to $\sim 3-4 \mathrm{~V}$ and $\mathrm{Li}_{x} \mathrm{Si}$ binaries such as $\mathrm{Li}_{15} \mathrm{Si}_{4}$ with $\sim 0.30 \mathrm{~V}$ [8]. Then $\mathrm{Li}_{2} \mathrm{ZrN}_{2}$ is found intermediate between oxide intercalation compounds and silicides [8] and [16].

In order to further assess these features, we analyze the charge density issued from the self consistent calculations using the AIM (atoms in molecules theory) approach [40] developed by Bader who devised an intuitive way of splitting molecules into atoms as based purely on the electronic charge density. Typically in chemical systems, the charge density reaches a minimum between atoms and this is a natural region to separate atoms from each other. Such an analysis can be useful when trends between similar compounds are examined; they do not constitute a tool for evaluating absolute ionizations. The results of computed charge changes $(\Delta Q)$ are such that they lead to neutral compounds: $\mathrm{Li}_{2} \mathrm{ZrN}_{2}: \mathrm{Li}:+1 ; \mathrm{Zr}:+3.28 ; \mathrm{N}:-2.64$, leading to an average charge transfer of \pm 5.28 electrons; "LiZrN" ${ }_{2}$ ": Li: $+1 ; \mathrm{Zr}:+3.33 ; \mathrm{N}:-2.16$, leading to an average charge transfer of \pm 4.34 electrons; and " $\mathrm{ZrN}_{2}{ }^{\prime}: \mathrm{Zr}$ $+3.4 ; \mathrm{N}$ : -1.7 with a charge transfer of \pm 3.4 electrons.

These values should be compared with the formal ones assuming a full departure/gain of electrons in the valence states of the atomic constituents: $\mathrm{Li}\left(2 s^{1}\right) ; \mathrm{Zr}\left(5 s^{2}, 4 d^{2}\right)$ and $\mathrm{N}\left(2 s^{2}, 2 p^{3}\right)$. With the three compositions considered, this leads to 6, 5 and 4 electrons transfer. Despite their larger magnitudes versus Bader charges, the values follow the same trend of decrease along the series of studied compositions. Then $\mathrm{Li}_{2} \mathrm{ZrN}_{2}$ has a closed shell like configuration with all quantum states occupied as follows for the valence states: $2 \times \mathrm{Li}\left(2 s^{0}\right) ; 1 \times \mathrm{Zr}\left(5 s^{0}, 4 d^{0}\right)$ and $2 \times \mathrm{N}\left(2 s^{2}, 2 p^{3+3}\right)$, i.e. with a departure of 6 electrons from $\mathrm{Li} / \mathrm{Zr}$ and an occupation of all the six $2 p$ states of the two nitrogen atoms. This is opposite to " $\square_{\mathrm{Li}} \mathrm{LiZrN}_{2}$ " and " $2 \square_{\mathrm{L}} \mathrm{ZrN}_{2}$ ", respectively with one and two less electrons, which should present holes in the valence band with consequences on the electronic properties such as the metal/insulating character determined from the density of states (DOS) - vide infra. Thus the passage from $\mathrm{Li}_{2} \mathrm{ZrN}_{2}$ to hypothetic " $\square_{\mathrm{L}} L \mathrm{LiZrN_{2 }}$ " and then to " $2 \square_{\mathrm{Li}} \mathrm{ZrN}_{2}$ " signals the decrease of the ionic character (removal of $\mathrm{Li}$ ) which is consequently largest for " $2 \square_{\mathrm{Li}} \mathrm{ZrN}_{2}$ ". It needs to be mentioned here that " $\mathrm{ZrN}_{2}$ " itself does not exist; only $\mathrm{N}$ excess $\mathrm{ZrN}$ is known $\left(\mathrm{ZrN}_{1.22}\right)$ [23]. This would indicate a destabilization of the compound if more than one lithium equivalent is removed, as the calculations pointed out. Consequently partial delithiation leading to $\mathrm{Li}_{2-x} \mathrm{ZrN}_{2}(x=\sim 1)$ is favored.

Finally the electrons transfer from $\mathrm{Li}$ to $\mathrm{N}$ can be illustrated by the electron localization function ELF [41] obtained from real space calculations: $\operatorname{ELF}=\left(1+\chi \sigma^{2}\right)^{-1}$. In this expression the ratio $\chi \sigma=D \sigma / D \sigma^{0}$ where $D \sigma=T \sigma-\nabla s-1 / 4(\nabla \rho \sigma)^{2} / \rho \sigma$ and $D \sigma^{0}=3 / 5\left(6 \pi^{2}\right)^{2 / 3} \rho \sigma^{5 / 3}$ correspond, respectively, to a measure of Pauli repulsion $(D \sigma)$ of the actual system and to the free electron gas repulsion $\left(D \sigma^{0}\right)$ and $T \sigma$ is the kinetic energy density. The ELF function is normalized between 0 (zero localization, blue areas) and 1 (strong localization, red areas) with the value of $1 / 2$ corresponding to a free electron gas behavior (green areas). Fig. 2 shows the ELF contour plots for horizontal planes containing Zr (a), N (b), $\mathrm{Li}$ (c) and a vertical plane comprising $\mathrm{Li}$ and $\mathrm{N}$. Whereas there is no electron localization around $\mathrm{Zr}$ (a) and Li (c, d) and green areas between them, there is a significant localization (orange-red areas) around $\mathrm{N}$ (b). This illustrates furthermore the charge density analysis above. The vertical plane along the $c$-axis (Fig. 2d) shows the layer-like structure of the compound with $\sim 0$ and $\sim 1$ ELF around Li and N, respectively.

\section{Electronicstructure and chemical bonding}

Using the calculated lattice parameters in Table 1 we analyze the electronicstructure and the chemicalbonding using all electron calculations with the full potential ASW method. The site projected density of states (PDOS) for $\mathrm{Li}_{2} \mathrm{ZrN}_{2}$, " $\square_{\mathrm{Li}} \mathrm{LiZrN}_{2}$ " and " ${ }_{\square_{\mathrm{LZ}}} \mathrm{ZrN}_{2}$ " are shown in Fig. 3.

From the presence of a band gap of $1.8 \mathrm{eV}$ at the top of the valence band (VB) $E_{\mathrm{V}}$, the zero energy along the $x$-axis is considered with respect to $E_{\mathrm{V}}$ and $\mathrm{Li}_{2} \mathrm{ZrN}_{2}$ is a small gap insulator, in agreement with its light-green color [24]. This follows from the closed shell like electronic configuration discussed above along with Bader charges. The VB shows a large contribution from nitrogen due to twice as much $\mathrm{N}$ versus $\mathrm{Zr}$ in the structure and to the charge transfer from $\mathrm{Li}$ and $\mathrm{Zr}$ to $\mathrm{N}$. Its $s$ states are low lying at $\sim-13 \mathrm{eV}$ and the $p$ states are found from $-5 \mathrm{eV}$ up to $E_{\mathrm{V}}$. Those states mix with itinerant $\mathrm{Zr} d$ states within the VB; $\mathrm{Zr}$ being an early $4 d$ element, its $d$ band is centered within the empty conduction band (CB). Li PDOS resemble the valence states of $\mathrm{Zr}$ and $\mathrm{N}$ and quantum mixing is expected between them as it is illustrated in next section of chemicalbonding. It is worth noting the dominating $N p$ states at the top of the VB which differentiate the nitrides from the oxides whose VB top is dominated by the $T$ states.

The removal of one equivalent of lithium leading to " ${ }_{L i} \mathrm{LiZrN}_{2}$ " involves one electron less so that the top of the VB is rigidly shifted within the nitrogen states (creation of a hole) as it can be shown in Fig. 3b. The compound is now 
metallic and energy reference is with respect to the Fermi level $\left(E_{\mathrm{F}}\right)$. This feature is also observed for " $2 \square_{\mathrm{Li}} \mathrm{ZrN}_{2}$ " in Fig. $3 c$ and a metallic like character is also observed. The decrease of the ionic character, as suggested from the Bader charges, is illustrated by a slightly broadened VB particularly for the $s$-like blocks, especially in the lithium-free hypothetic compound. The resemblance between the DOS in the three panels shows that lithium plays little role in the change of the structure which is mainly ensured by $\mathrm{Zr}$ and $\mathrm{N}$ binding. Similar changes in the electronicstructure occur for the various intercalated phases of $\mathrm{ZrN}$ versus $\mathrm{Li}_{x} \mathrm{ZrN}$ and $\mathrm{ZrNCl}$ versus $\mathrm{Li}_{x} \mathrm{ZrNCl}$. For details we refer to a recent overview [42].

This is further exhibited in Fig. 4 showing the COOP for the three compounds $\mathrm{Li}_{2} \mathrm{ZrN}_{2}$ (a) " $\square_{\mathrm{Li}} \mathrm{LiZrN}_{2}$ " (b) and "2 $\square_{\mathrm{Li}} \mathrm{ZrN}_{2}$ " (c) accounting for atom multiplicities (Table 1). The whole range of the VB is of bonding character (positive COOP) for the main interaction, $\mathrm{Zr}-\mathrm{N}$ as well as for $\mathrm{Li}-\mathrm{N}$. The $\mathrm{Li}-\mathrm{Zr}$ bond is negligible as it can be expected from the electropositive nature of both and their large separation $(\sim 2.8 \AA)$. The $\mathrm{N}-\mathrm{N}$ interaction is of half bonding/half antibonding character so that the large N PDOS at the top of the VB is due to antibonding (repulsive) N-N states. Interestingly, the $\mathrm{N}-\mathrm{N}$ antibonding character is of less magnitude from $\mathrm{Li}_{2} \mathrm{ZrN}_{2}$ (Fig. 4a) to " $\square_{\mathrm{Li}} \mathrm{LiZrN}{ }_{2}$ " (Fig. 4b) and " $\square_{{ }_{\mathrm{Li}} \mathrm{LiZrN}}$ " (Fig. 4c) as the Fermi level is moved down within the VB (cf. DOS section). This is also concomitant with the larger binding energy obtained from above energy differences calculated for $\mathrm{Li}_{2} \mathrm{ZrN}_{2}$ and " $\square \mathrm{Li} \mathrm{LiZrN}_{2}$ ".

\section{Acknowledgments :}

This work was financially supported by the Deutsche Forschungsgemeinschaft (PAK 177) and the Bundesministerium für Forschung und Technologie (LiVe-Lithium-Verbundstrukturen within the program LIB 2015). Support from the Centre Supérieur de la Recherche (CSR)-USEK-Lebanon is also gratefully acknowledged.

\section{References}

1. M. Yoshio, R.J. Brodd, A. Kozawa (Eds.), Lithium-Ion Batteries: Science and Technologie, Springer, New York (2009).

2. K. E. Aifantis, S.A. Hackney, R.V. Kumar (Eds.), High Energy Density Lithium Batteries, Wiley-VCH, Weinheim (2010).

3. R. A. Huggins. Lithium alloys electrodes. D. Claus, J.O. Besenhard (Eds.), Handbook of Battery Materials, Wiley-VCH, Weinheim (2011), pp. 405-432.

4. R. Pöttgen, T. Dinges, H. Eckert, P. Sreeraj, H.-D. Wiemhöfer, Z. Phys. Chem., 224 (2010), p. 1475.

5. V.S. Kolosnitsyn, E.V. Karaseva, Russ. J. Electrochem., 44 (2008), p. 506.

6. J. Cabana, L. Monconduit, D. Larcher, M.R. Palacín, Adv. Mater., 22 (2010), p. E170.

7. D.H. Gregory, Coord. Chem. Rev., 215 (2001), p. 301.

8. Y. Kubota, M.C.S. Escaño, H. Nakanishi, H. Kasai, J. Appl. Phys., 102 (2007), p. 053704.

9. A. Honda, S. Higai, N. Wada, Y. Sakabe, J. Phys. Chem. Solids, 69 (2008), p. 1353.

10. T. Dinges, U. Ch. Rodewald, S.F. Matar, H. Eckert, R. Pöttgen, Z. Anorg. Allg. Chem., 635 (2009), p. 1894.

11. T. Dinges, R.-D. Hoffmann, L. van Wüllen, P. Henry, H. Eckert, R. Pöttgen, J. Solid State Electrochem., 15 (2011), p. 237.

12. A. Kuhn, P. Sreeraj, R. Pöttgen, H.-D. Wiemhöfer, M. Wilkening, P. Heitjans, J. Am. Chem. Soc., 133 (2011), p. 11018.

13. A. Kuhn, M. Wilkening, S. Puravankara, R. Pöttgen, H.-D. Wiemhöfer, P. Heitjans, Angew. Chem., 123 (2011), p. 12305.

14. S. Dupke, T. Langer, R. Pöttgen, M. Winter, H. Eckert, Solid State NMR 40, in press. http://dx.doi.org/10.1016/j.ssnmr.2011.09.002

15. T. Langer, S. Dupke, H. Eckert, S.F. Matar, M. Winter, R. Pöttgen, Solid State Sci., 14 (2012), p. 367.

16. S.F. Matar, R. Pöttgen, N. Ouaini, Solid State Sci., 14 (2012), p. 375.

17. R. Juza, Adv. Inorg. Radiochem., 9 (1966), p. 81.

18. R. Juza, K. Langer, K. von Benda, Angew. Chem., 80 (1968), p. 373.

19. N.E. Brese, M. O'Keeffe, Struct. Bonding, 79 (1992), p. 307.

20. R. Niewa, H. Jacobs, Chem. Rev., 96 (1996), p. 2053.

21. R. Kniep, Pure Appl. Chem., 69 (1997), p. 185.

22. R. Niewa, F.J. DiSalvo, Chem. Mater., 10 (1998), p. 2733.

23. A.P. Palisaar, R. Juza, Z. Anorg. Allg. Chem., 384 (1971), p. 1

24. R. Niewa, H. Jacobs, Z. Kristallogr., 210 (1995), p. 513.

25. O.V. Volkova, V.P. Obrosov, N.N. Batalov, Z.S. Martem'yanova, Elektrokhimiya, 29 (1993), p. 1372.

26. O.V. Zheltonozhko, V.P. Obrosov, N.N. Batalov, I.V. Korzun, in: Proceedings of the Electrochemical Society $93-9$ on Molten Molten Salt Chemistry and Technology, 1993, p. 578.

27. P. Hohenberg, W. Kohn, Phys. Rev., 136 (1964), p. B864.

28. W. Kohn, L.J. Sham, Phys. Rev., 140 (1965), p. A1133. 
29. G. Kresse, J. Furthmüller, Phys. Rev. B, 54 (1996), p. 11169.

30. G. Kresse, J. Joubert, Phys. Rev. B, 59 (1999), p. 1758.

31. P.E. Blöchl, Phys. Rev. B, 50 (1994), p. 17953.

32. J. Perdew, K. Burke, M. Ernzerhof, Phys. Rev. Lett., 77 (1996), p. 3865.

33. W.H. Press, B.P. Flannery, S.A. Teukolsky, W.T. Vetterling, Numerical Recipes, Cambridge University Press, New York (1986).

34. M. Methfessel, A.T. Paxton, Phys. Rev. B, 40 (1989), p. 3616.

35. H.J. Monkhorst, J.D. Pack, Phys. Rev. B, 13 (1976), p. 5188.

36. A.R. Williams, J. Kübler, C.D. Gelatt, Phys. Rev. B, 19 (1979), p. 6094.

37. V. Eyert, The Augmented Spherical Wave Method-A Comprehensive Treatment, Lecture Notes in Physics, Springer, Heidelberg (2007)

38. R. Hoffmann, Angew. Chem. Int. Ed. Engl., 26 (1987), p. 846.

39. M.K. Aydinol, A.F. Kohan, G. Ceder, K. Cho, J. Joannopoulos, Phys. Rev. B, 56 (1997), p. 1354.

40. R. Bader, Chem. Rev., 91 (1991), p. 893

41. A.D. Becke, K.E. Edgecombe, J. Chem. Phys., 92 (1990), p. 5397.

42. C.M. Schurz, L. Shlyk, T. Schleid, R. Niewa, Z. Kristallogr., 226 (2011), p. 395. 


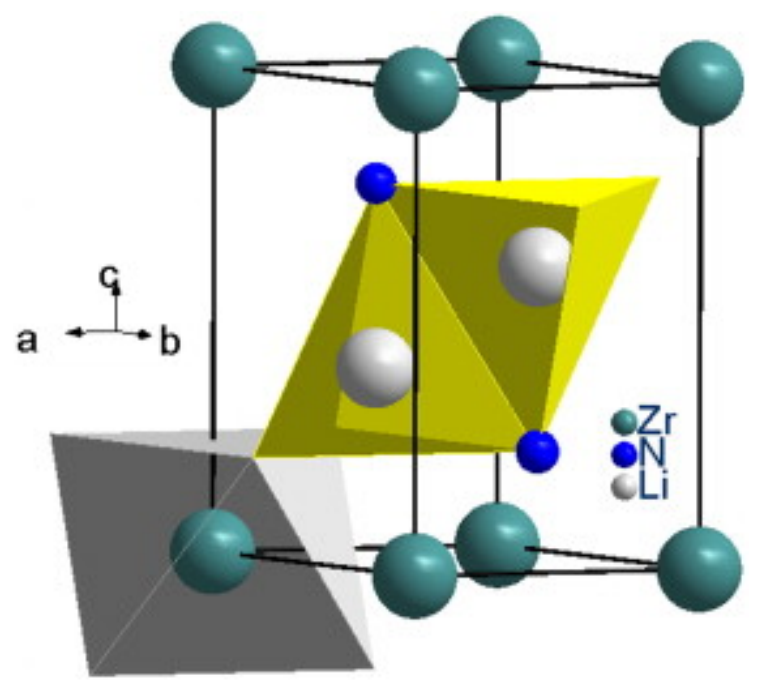

Fig. 1. The trigonal structure of $\mathrm{Li}_{2} \mathrm{ZrN}_{2}$. The edge-sharing $\mathrm{LiN}_{4}$ tetrahedra and one $\mathrm{ZrN}_{6}$ octahedron are emphasized.

a

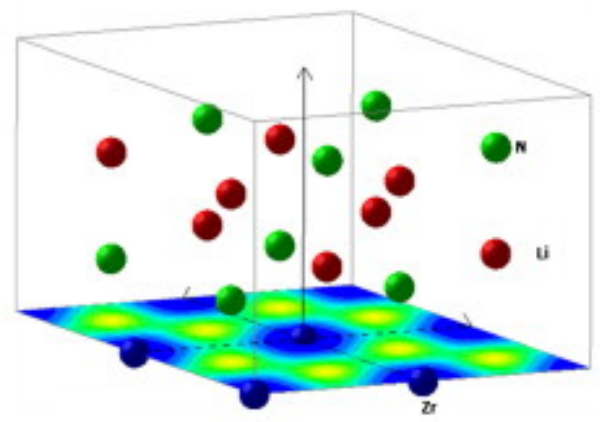

C

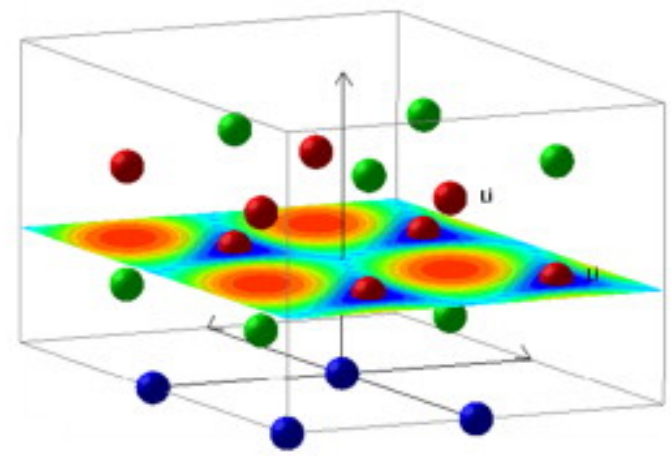

b

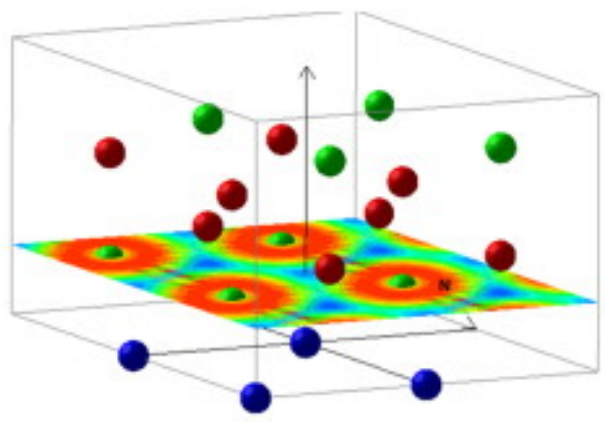

d

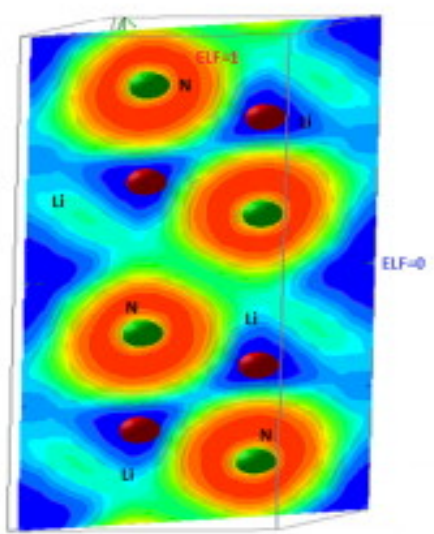

Fig. 2. Electron localization function ELF plots for $\mathrm{Li}_{2} \mathrm{ZrN}_{2}$ over 4 adjacent cells, showing (a) the basal plane at $z=0$ containing $\mathrm{Zr}$, (b) the plane comprising N, (c) the plane containing Li, and (d) vertical plane with Li and N. Blue, green and red areas designate weak, free electron like and strong localizations respectively (see text). (For interpretation of the references to color in this figure legend, the reader is referred to the web version of this article). 

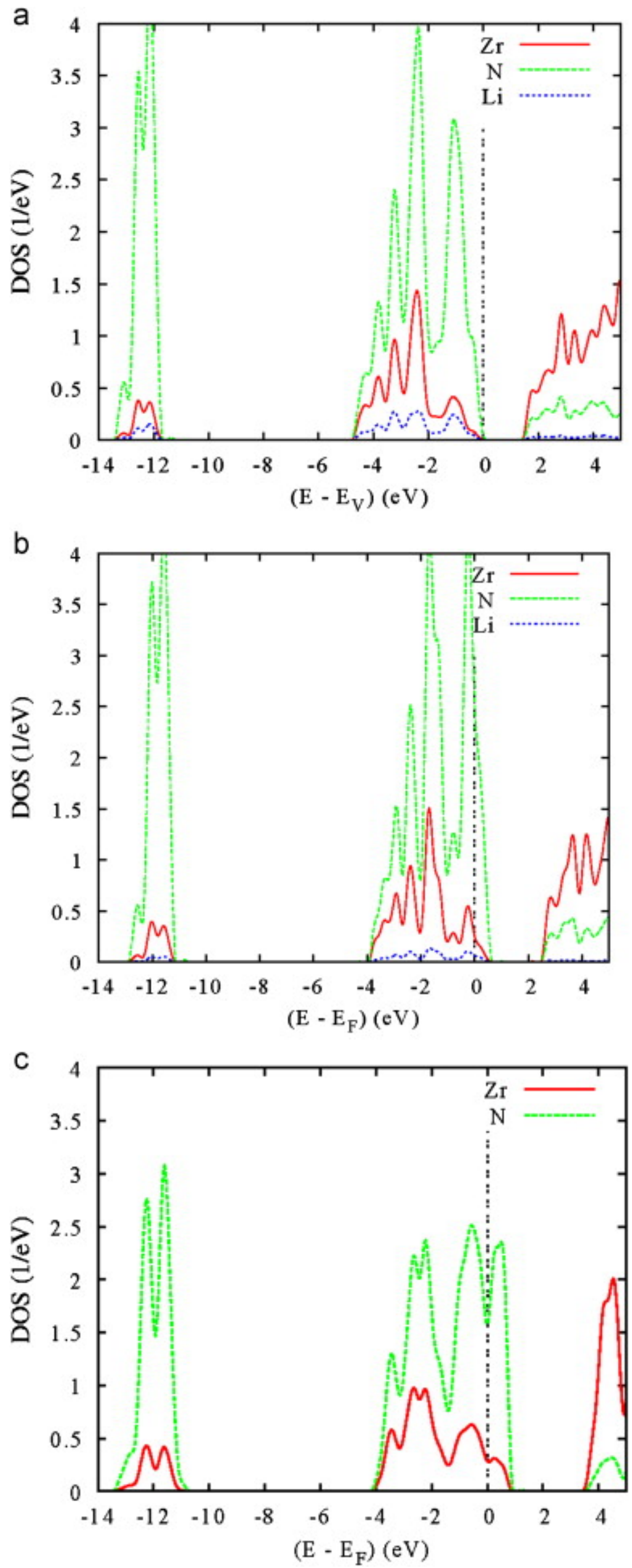

Fig. 3. Site projected density of states (PDOS) for $\mathrm{Li}_{2} \mathrm{ZrN}_{2}(a)$, $\square_{\mathrm{Li}} \mathrm{LiZrN}_{2}$ (b) and $2 \square_{\mathrm{L}} \mathrm{ZrN}_{2}$ (c) for all atom multiplicities. 

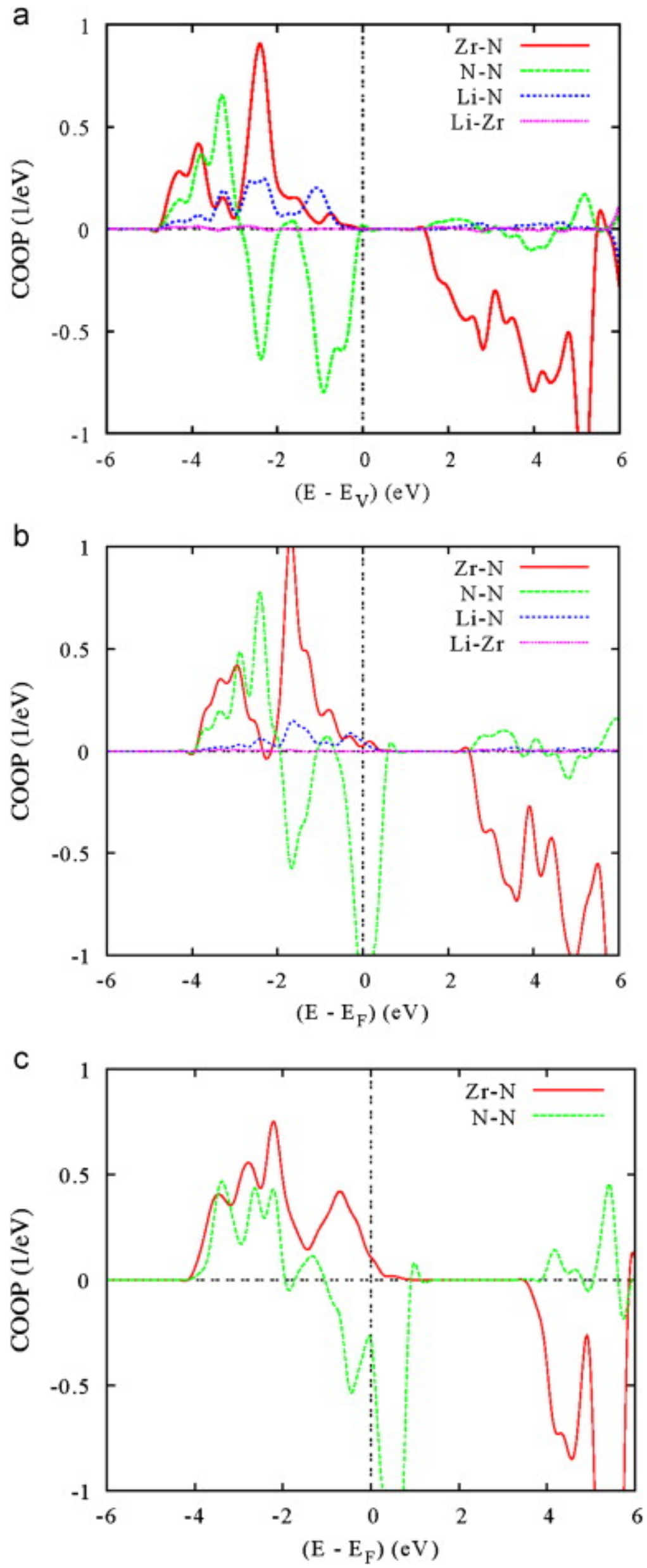

Fig. 4. Chemical bonding in $\mathrm{Li}_{2} \mathrm{ZrN}_{2}(a), " \square_{\mathrm{Li}} \mathrm{LiZrN}_{2}$ " (b) and " $2_{\mathrm{L}_{\mathrm{L}}} \mathrm{LiZrN}_{2}$ " (c) for all atom multiplicities. 
Table 1

$\mathrm{Li}_{2} \mathrm{ZrN}_{2}$ and hypothetic $\mathrm{Li}$ de-intercalated phases. Experimental and calculated (italics) lattice parameters. $\mathrm{Zr}(1 a)$ at $(000)$.

\begin{tabular}{|c|c|c|c|}
\hline$P 3 ̄ m 1$ & $\mathrm{Li}_{2} \mathrm{ZrN}_{2}$, exp. $[24] /$ calc. & " $\square_{\mathrm{L}} \mathrm{LiZrN}_{2}$ " calc. & Li-free $\mathrm{L}_{2} \mathrm{ZrN}_{2}\left(2 \square_{\mathrm{L}} \mathrm{ZrN}_{2}\right)$ calc. \\
\hline$a(\dot{\AA})$ & $3.285 / 3.28$ & 3.29 & 3.38 \\
\hline$c(\bar{A})$ & $5.461 / 5.44$ & 5.34 & 4.33 \\
\hline$c / a$ & $1.66 / 1.66$ & 1.62 & 1.28 \\
\hline$V\left(\hat{\AA}^{3}\right)$ & $51.036 / 50.63$ & 49.95 & 41.20 \\
\hline $\mathrm{N}(2 d)(1 / 32 / 3 z)$ & $z=0.223 / 0.228$ & $z=0.207$ & $z=0.23$ \\
\hline $\mathrm{Li}(2 d)\left(1 / 32 / 3 z^{\prime}\right)$ & $z^{\prime}=0.613 / 0.614$ & $z^{\prime}=0.417$ & $z^{2}:-$ \\
\hline \multirow{2}{*}{ Shortest distances $(\tilde{A})$} & Li-N: $2.09 / 2.08$ & Li-N: 1.95 & Li-N: - \\
\hline & $\mathrm{Zr}-\mathrm{N}: 2.25 / 2.26$ & $\mathrm{Zr}-\mathrm{N}: 2.17$ & $\mathrm{Zr}-\mathrm{N}: 2.19$ \\
\hline Energy $(e V)$ & -34.60 & -30.22 & -24.82 \\
\hline
\end{tabular}

